\title{
Seroprevalence and risk factors associated with Pseudorabies virus infection in Tibetan pigs in Tibet
}

\author{
Qingxia Wu ${ }^{{ }^{* *}}$, Hui Zhang ${ }^{2 \dagger} \mathbb{B}$, Hailong Dong ${ }^{1}$, Khalid Mehmood ${ }^{2,3}$, Zhenyu Chang ${ }^{1}$, Kun Li ${ }^{2}$, Suozhu Liu', \\ Mujeeb Ur Rehman ${ }^{2}$, Fazul Nabi ${ }^{2}$, Muhammad Tariq Javed ${ }^{4}$, Hongyun Zhu ${ }^{1 *}$ and Jiakui Li $^{1,2^{*}}$
}

\begin{abstract}
Background: Pseudorabies (PR) is an important emerging infectious disease that is characterized by fever, extreme itching and encephalomyelitis. However, it is still unclear whether Tibetan pigs are exposed to Pseudorabies virus (PRV) or not.

The present study was conducted to investigate the seroprevalence of PRV infection in Tibetan pigs in Nyingchi area of Tibet through enzyme-linked immunosorbent assay (ELISA). A total of 368 serum samples from Tibetan pigs were collected during 2015.

Results: Results showed that 58 (15.76\%) samples were found positive for PRV antibodies with further distribution of 18. 23\%, 13.42\% and 6.25\% from Nyingchi, Mainling and Gongbo'gyamda areas on the Tibetan plateau, respectively; along with $12.10 \%, 17.71 \%$ and $17.57 \%$ prevalence of PRV in juveniles, sub-adults and adults, respectively. The prevalence of PRV infection between male (14.61\%) and female (16.84\%) showed non-significant difference $(P>0.05)$. The risk factors of infection were found to be associated with feed type, age and altitude.
\end{abstract}

Conclusions: The present study depicts a serious concern with a new emerging infectious disease in Tibetan pigs in Tibet, China.

Keywords: Pseudorabies (PR), Seroprevalence, Risk factors, Tibetan pigs, Tibet

\section{Background}

Pseudorabies (PR) or Aujeszky's disease is one of the highly contagious diseases, which is responsible for devastating outbreaks and considerable economic losses to the swine industry in China. It is caused by Pseudorabies virus (PRV), which is the member of genus Varicellovirus, belonging to subfamily Alphaherpesvirinae, and family Herpesviridae [1-3]. The domestic and feral pigs are the main natural hosts of this disease [4]. The PR is usually characterized by reproductive disorders such as miscarriage, fetal death and mummified fetus. The mortality rate of newborn piglets and abortion are up to $100 \%$ in some cases [5]. The infection in growing pigs usually leads to decrease in semen quality, and even death in some cases.

\footnotetext{
*Correspondence: wuqx2014@sina.com; zh0561@sina.com; lijk210@sina.com ${ }^{\dagger}$ Equal contributors

'Key laboratory of clinical veterinary medicine in Tibet, Tibet Agriculture and Animal Husbandry College, Linzhi 860000, Tibet, People's Republic of China Full list of author information is available at the end of the article
}

Pseudorabies is highly hazardous and widely distributed contagious disease, and world health organization (OIE) has listed PR as class B animal disease, and listed as the secondary kind of animal disease in China [6].

The PR is an endemic and widespread swine disease in China from the last 5 years, and it is planned as one of the priority swine diseases for control $[7,8]$. Recently, with the use of PRV vaccines, this situation has been controlled on large-scale pig farms [2]; however, the prevention and control of PR on small pig farms and free-ranging pigs is still a big challenge [9]. The regional elimination and eradication program of PRV is required in China as no region is declared free from PRV yet [6].

In China, PRV was first reported in cats in 1947, and subsequently found in swine [7]. Tibetan pig is relatively ancient in origin, indigenous and rare plateau type pig breed in the world and is the only high-altitude pasture pig breed in China $[10,11]$. It is distributed in the 
Qinghai-Tibetan Plateau in China (Qinghai, Sichuan, Yunnan and eastern Tibet region). The seroprevalence of PRV infection in pigs in Qinghai, Sichuan and Yunnan areas is reported in local Chinese journals but hardly accessible to international readers, and that is summarized in Table 1.

To date, no survey has been conducted to elucidate PRV infection and risk factors on PR in Tibetan pigs. The current study is conducted for the first time on seroprevalence of PRV infection in Tibetan pigs and it provides a reference basis for the PRV research in the future.

\section{Methods}

\section{The study sites}

The present study was carried out in Nyingchi Prefecture in southeastern Tibet, China. This area is geographically isolated from Tibet and Sichuan Provinces by Himalayan Mountains, and shares its borders with Yunnan and Qinghai Provinces [10-12]. Nepal is located on the southwest, while India and Myanmar in the south of the Nyingchi. The average elevation of the surveyed area is more than $3100 \mathrm{~m}$ above the sea level (Fig. 1).

\section{Samples}

A total of 368 blood samples were collected from different slaughterhouses of three counties (Nyingchi, Mainling and Gongbo'gyamda) in Tibet during 2015 (Fig. 1). All samples were collected from non-vaccinated pigs. The blood samples were collected by anterior vena cava of pigs. After collection of blood samples, each sample was centrifuged at $3000 \times \mathrm{g}$ for $20 \mathrm{~min}$ to separate the serum which was subsequently stored at $-20{ }^{\circ} \mathrm{C}$. These samples were transported in ice bag to Huazhong Agricultural University for further analysis.

The serum samples were used for detection of IgG antibodies for PRV by a commercially available ELISA kit (Wuhan Keqian Biology Co., Ltd). All the protocols were followed according to the manufacturer's instructions and the results were interpreted accordingly.

The results were based on the critical value (cut off) according to the formula: Critical Value $=$ the average of Negative control $\mathrm{OD}_{630}+0.15$. The validity was ensured as: the average of Negative control $\mathrm{OD}_{630}$ - Positive control $\mathrm{OD}_{630}$ was $\geq 0.4$. The samples were interpreted as negative: if sample $\mathrm{OD}_{630} /$ Negative controlOD 630 was $>0.7$ (cut off). The samples were interpreted as

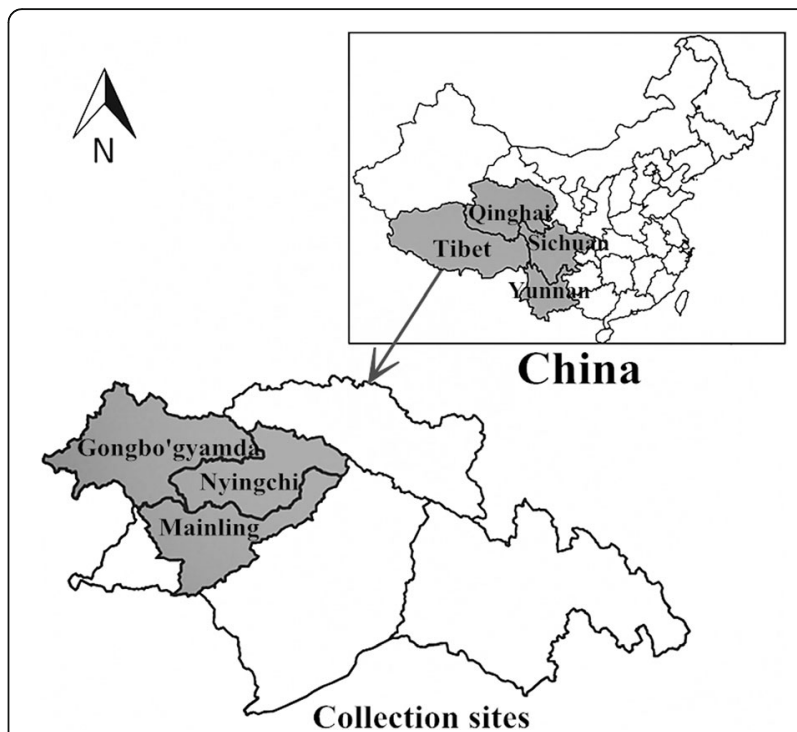

Fig. 1 Geographic location of Aujeszky's disease virus in four provinces, China. Map was created by using Mapinfo software; data are from the National Fundamental Geographic System website (www.dituhui.com)

positive if sample $\mathrm{OD}_{630} /$ Negative control $\mathrm{OD}_{630}$ was $\leq 0.7$ (cut off).

\section{Statistical analysis}

The data were analyzed by the chi-square test using the procedure of SAS (Statistical Analysis System, Version 8.0). Statistically significant levels within factors and interactions were recognized, when probability $(P)$ value was found $P<0.05$. Odds-ratios were determined for the risk factors associated PRV along with $95 \%$ confidence intervals.

\section{Results}

\section{Seroprevalence of PRV}

A total of $35(16.36 \%)$ out of 214 serum samples were found positive for antibodies to PRV in large-scale Tibetan pig farms, with the further distribution of 23 (20.00\%), 11 (12.64\%) and 1 (8.33\%) from Nyingchi, Mainling and Gongbo'gyamda areas, respectively. Antibodies against PRV were detected in 23 (14.94\%) of 154 serum samples by ELISA in free-ranging Tibetan pigs, with the further distribution of 14 (15.91\%), 9 (14.52\%) and 0 from Nyingchi, Mainling and Gongbo'gyamda areas, respectively. The results were statistically

Table 1 Prevalence of Aujeszky's disease virus infection in pigs and in Tibetan pig distribution province, China

\begin{tabular}{lllll}
\hline Province & No. tested & Test method & Positive (\%) & Reference \\
\hline Qinghai & 456 & ELISA & $4.80 \%$ & Xiaoying Qi et al. 2015 (in Chinese) \\
Sichuan & 1110 & ELISA & $17.61 \%$ & Kui Nie et al. 2013 (in Chinese) \\
Yunnan & 1164 & ELISA & $35.40 \%$ & Xianghua Shu et al. 2010 (in Chinese) \\
Tibet & 368 & ELISA & $15.76 \%$ & In present study \\
\hline
\end{tabular}


significant between large-scale and free-ranging Tibetan pigs $(P<0.05)$, as well as among different regions (Table 2).

The results of this study showed that a much higher proportion of seropositive were sub-adults (17.71\%), followed by adults (17.57\%) and juveniles (12.10\%). There was non-significant difference between the subadults or adults and juveniles as shown in Table 3. The results revealed that the prevalence in female and male Tibetan pigs' was $14.61 \%$ and $16.84 \%$, respectively. The seroprevalence was $21.43 \%, 15.70 \%$ and $11.11 \%$ at the altitude of $2800 \mathrm{~m}, 3200 \mathrm{~m}$ and $3700 \mathrm{~m}$, respectively. Statistical analysis revealed that the prevalence of PRV was significantly different $(P<0.05)$ at different altitudes.

\section{Risk factors for seropositivity of PRV}

We evaluated four pre-identified probable risk factors including age, sex, feed type and altitude. Our results showed that feed type, altitude and age were significantly associated with an increase risk of PRV seropositivity in Tibetan pigs (Table 3 ).

\section{Discussion}

Pseudorabies virus has been reported in many countries and it was first reported in the 19th century in the United States [7, 13, 14]. Infectious diseases have been serious threat for animal health and productivity in developing countries [15-19]. China is the world's largest producer of swine, and PRV has become a major infectious disease threat to pig industry and causes serious issue. The lack of awareness and control measures against common infectious disease is a major cause of PRV in population. Although, the vaccination program was applied on many pig farms, but there were often occurrence and epidemic of this disease. The previous reports showed that the prevalence of PRV infection in pigs in Qinghai (4.80\%), Sichuan (17.61\%) and Yunnan (35.40\%) provinces were very serious [5, 20, 21]. Tibetan pigs are mainly distributed in Qinghai, Sichuan, Yunnan and the eastern Tibet region. There are no previous published data regarding the prevalence of PRV infection in pigs. To the best of our knowledge, the present study provides the first report of PRV infection in Tibetan pigs.
Table 3 Association between Tibetan pig characteristics and Aujeszky's disease virus serological status with corresponding chi square $\left(x^{2}\right), p$-value, odds ratio (OR), and confidence interval (Cl) Characteristic No. tested Positive $95 \% \mathrm{Cl}$ MHChi-sq OR/ $\mathrm{N} \% \quad P$ value reciprocal

\begin{tabular}{lllllll}
\hline Age & & & & & & \\
Juveniles & 124 & 15 & 12.10 & $6.9-19.2$ & $P=0.229$ & - \\
Sub-adults & 96 & 17 & 17.71 & $10.7-26.8$ & - \\
Adults & 148 & 26 & 17.57 & $11.8-24.7$ & - \\
Sex & & & & & & \\
Male & 178 & 26 & 14.61 & $9.8-20.7$ & - & $0.84 / 1.18$ \\
Female & 190 & 32 & 16.84 & $11.8-22.9$ & - & \\
Feed type & & & & & & \\
Free-ranging & 154 & 23 & 14.94 & $9.7-21.6$ & - & $0.90 / 1.11$ \\
Large-scale & 214 & 35 & 16.36 & $11.7-22.0$ & - & \\
Altitude & & & & & & \\
$3700 \mathrm{~m}$ & 135 & 15 & 11.11 & $6.4-17.7$ & $P=0.027$ & - \\
$3200 \mathrm{~m}$ & 121 & 19 & 15.70 & $9.7-23.4$ & - \\
$2800 \mathrm{~m}$ & 112 & 24 & 21.43 & $14.2-30.2$ & - \\
\hline & & & & & &
\end{tabular}

In our study, the overall PRV seroprevalence was $15.76 \%$ in Tibetan pigs in Tibet, which was lower than that reported in pigs in Shandong (56.7\%), Henan (53.7\%), Beijing (24.0\%), Tianjing (17.1\%), Hebei (16.9\%) and Liaoning $(16.8 \%)[1,8,22,23]$. The low seropositivity of PRV in Tibetan pigs may be due to the evolution difference and unique characteristics of the plateau environment. On the other hand, Tibet's unique mountains and rivers build a natural barrier to prevent or minimize the chances of spread of PRV.

Our results showed PRV infection among the different age groups of Tibetan pigs, a higher prevalence was detected in sub-adult $(17.71 \%)$ or adult $(17.57 \%)$ pigs, compared with the juveniles (12.10\%). Some previous studies have also observed a higher seroprevalence of Aujeszky disease virus (ADV) between adults and juveniles [24]. However, non-significant difference $(P>0.05)$ was observed in $P R$ seroprevalence between sex and feed type Tibetan pigs, which was different than the previous report [24]. Our results suggested that the incidence of PR was not related to the gender and feed type and there are several other possible reasons for this in Tibetan

Table 2 Descriptive characteristics and estimates of Aujeszky's disease virus seroprevalence at large-scale Tibetan pigs and free-range Tibetan pigs

\begin{tabular}{|c|c|c|c|c|c|c|}
\hline \multirow[t]{2}{*}{ Variable } & \multicolumn{2}{|c|}{ Large-scale Tibetan pigs } & \multicolumn{2}{|c|}{ Free-ranging Tibetan pigs } & \multicolumn{2}{|l|}{ Total } \\
\hline & Samples & NO. Positive (\%) & Samples & NO. Positive (\%) & Samples & NO. Positive (\%) \\
\hline Nyingchi & 115 & $23(20.00 \%)$ & 88 & $14(15.91 \%)$ & 203 & $37(18.23 \%)$ \\
\hline Mainling & 87 & $11(12.64 \%)$ & 62 & $9(14.52 \%)$ & 149 & $20(13.42 \%)$ \\
\hline Gongbo'gyamda & 12 & $1(8.33 \%)$ & 4 & 0 & 16 & $1(6.25 \%)$ \\
\hline
\end{tabular}


pigs. Firstly, it may be due to living in a similar environment and free-ranging system and secondly, each pig has the same chance to contact PRV $[11,25]$.

$\mathrm{Hu}$ et al. reported that the probability of reintroduction of PRV infection in large-scale Tibetan pig farms was positively different with free-ranging Tibetan pig farms [22]. However, our study has shown that feed type is associated with the infection of PRV. The subsequent univariate analysis indicated that the large-scale Tibetan pig farms were at higher risk for PRV seropositivity than free-ranging Tibetan pigs (OR: 1.11). Tibetan pigs are mainly fed by grazing in open environment [26]. Under such conditions, this animal gets more chance to expose to the external environment. Among these, sub-adults and adults have the longest time of outdoor activities which increases the risk of infection as compared with the juvenile Tibetan pigs.

Tibet is located in the Himalaya region and have high altitude with low temperature $[10,12,26]$. The local herdsmen have very less chance of interacting with the outside, which is not conducive to the survival of PRV. Tibet has unique mountains and rivers, forming a natural barrier structure, which is a different than reported earlier [27]. However, our study found that Tibetan pigs have been exposed to PRV and we discovered that the pigs living at low altitude $(2800 \mathrm{~m})$ were at higher risk for PRV seropositivity than those living at high altitude $(3200 \mathrm{~m}$ and $3700 \mathrm{~m})$. Current study reported PRV in Tibetan pig, and thus preventive and hygienic measures are suggested to minimize the serious economic losses. The vaccination, regular disinfection, and isolation of infected pigs are important to prevent the spread of PR from a particular area.

\section{Conclusions}

The present study demonstrated the seroprevalence of PRV infection in Tibetan pigs, and found that feed type, age and altitude are major risk factors associated with PRV herd seropositivity and possible source for the spread of PRV in Tibetan pigs.

\section{Abbreviations \\ ELISA: Enzyme-linked immunosorbent assay; PR: Pseudorabies; \\ PRV: Pseudorabies virus; SAS: Statistical Analysis System}

\section{Acknowledgments}

The authors thanked Jiakui Li (Huazhong Agricultural University) for his positive advice on experimental design.

\section{Funding}

This study was supported Key Science Fund of Science and Technology Agency of Tibet Autonomous Region, Key laboratory of clinical veterinary medicine in Tibet in project designing and sample collection and projects in the National Science \& Technology Pillar Program during the 12th Five-year Plan Period (2012BAD3B03) helped in data interpretation. Research and Application of Non-Grain Feed Development for Tibetan pigs in winter and spring helped in manuscript drafting.
Availability of data and materials

All data is presented in this article is available upon request to corresponding author (Qingxia Wu).

\section{Authors' contributions}

JK L, HY Z, HZ, QX W, HL D, KL, KM, MU R, SZ L, ZY C, FN and MTJ contributed to study design, data analysis, and manuscript writing along with participated sufficiently in final approval of the paper. JK L, HY Z, HZ and QX W conceived and designed the experiments; $H L D, K L$ and $M U R$ performed the experiments; SZ L, ZY C, FN, and MTJ contributed reagents, materials, and analysis tools; SZ L, ZY C, and MTJ revised the manuscript. Furthermore, all the authors have read and approved the final manuscript.

\section{Ethics approval}

All experiments were approved and reviewed by the Animal Welfare and Ethics Committee of Huazhong Agricultural University, Wuhan, China following the national legislations regarding animal's welfare. Furthermore, the owners of the slaughterhouses were inquired for getting verbal permission to conduct this study.

\section{Consent for publication}

Not applicable

\section{Competing interests}

The authors declare that they have no competing interests.

\section{Publisher's Note}

Springer Nature remains neutral with regard to jurisdictional claims in published maps and institutional affiliations.

\section{Author details}

'Key laboratory of clinical veterinary medicine in Tibet, Tibet Agriculture and Animal Husbandry College, Linzhi 860000, Tibet, People's Republic of China. ${ }^{2}$ College of Veterinary Medicine, Huazhong Agricultural University, Wuhan 430070, People's Republic of China. ${ }^{3}$ University College of Veterinary \& Animal Sciences, the Islamia University of Bahawalpur, Bahawalpur 63100 Pakistan. ${ }^{4}$ Departmet of Pathology, University of Agriculture, Faisalabad, Pakistan.

Received: 24 February 2017 Accepted: 15 January 2018

Published online: 22 January 2018

\section{References}

1. An TQ, Peng JM, Tian ZJ, Zhao HY, Li N, Liu YM, et al. Pseudorabies virus variant in Bartha-K61-vaccinated pigs, China, 2012. Emerg. Infect. Dis. 2015;19:1749-55.

2. Gu Z, Dong J, Wang J, Hou C, Sun H, Yang W, et al. A novel inactivated gE/ gl deleted Pseudorabies virus (PRV) vaccine completely protects pigs from an emerged variant PRV challenge. Virus Res. 2015;195:57-63.

3. Klupp BG, Hengartner CJ, Mettenleiter TC, Enquist LW. Complete, annotated sequence of the pseudorabies virus genome. J Virol. 2004;78:424-40.

4. Kluge JP, Beran GW, Hill HT, Platt KB. Pseudorabies (Aujeszky's disease). Disease Swine. 1999;8:233-46.

5. Nie K, Li ZQ, Zeng Z, Yang ZL, Luo L. Seroepidemiological investigation and risk factor analysis of Pseudorabies in finishing pigs in some regions of Sichuan and Chongqing. J. Southwest Univ. 2013;35:7-12. (in Chinese)

6. The State Council of the People's Republic of China, National middle-tolong term plan for animal disease control (2012-2020), the bulletin of the state Council of the People's republic of China, 2012.

7. Sun Y, Luo Y, Wang CH, Jin Y, Na L, Song K. Control of swine pseudorabies in china: opportunities and limitations. Vet Microbiol. 2016;183:119-24.

8. Tong GZ, Chen HC. Pseudorabies epidemic status and control measures in China. China Journal Veterinary Science. 1999;19:1-2. (in Chinese)

9. Wang CH, Yuan J, Qin H, Luo Y, Cong X, Li Y, et al. A novel gE-deleted Pseudorabies virus (PRV) provides rapid and complete protection from lethal challenge with the PRV variant emerging in Bartha-K61-vaccinated swine population in China. Vaccine. 2014;32:3379-85.

10. Zhang H, Mujeeb UR, Li K, Luo HQ, Lan YF, Fazul N, et al. Epidemiologic survey of Japanese encephalitis virus infection, Tibet, China, 2015. Emerg Infect Dis. 2017;23(6):1023-4.

11. Zhang H, Mujeeb UR, Li K, Luo HQ, Lan YF, Fazul N, et al. Antimicrobial resistance of Escherichia coli isolated from Tibetan piglets suffering from white score diarrhea. Pak Vet J. 2016;37(1):43-6. 
12. Zhang H, Luo HQ, Mujeeb UR, Fazul N, Li K, Lan YF, et al. Evidence of JEV in Culex tritaeniorhynchus and pigs from high altitude regions of Tibet, China. J. Vector Borne Dis. 2017;54(1):69-73.

13. Wu R, Bai CY, Sun JZ, Chang SK, Zhang X. Emergence of virulent pseudorabies virus infection in northern China. J. Vet. Sci. 2013;14:363-5.

14. Gortázar C, Vicente J, Fierro Y, León L, Cubero MJ, Gonzalez M. Natural Aujeszky's disease in a Spanish wild boar population. Ann N Y Acad Sci. 2012;969:210-2.

15. Ali F, Hussain R, Qayyum A, Gul ST, lqbal Z, Hassan MF. Milk somatic cell counts and some hemato-biochemical changes in sub-clinical mastitic dromedary she-camels (Camelus dromedarius). Pak Vet J. 2016;36:405-8.

16. Elhaig MM, Selim A, Mahmoud MM, El-Gayar EK. Molecular confirmation of Trypanosoma evansi and Babesia bigemina in cattle from lower Egypt. Pak Vet J. 2016;36:409-14.

17. Qayyum A, Khan JA, Hussain R, Avais M, Ahmad N, Khan MS. Investigation of milk and blood serum biochemical profile as an indicator of subclinical mastitis in Cholistani cattle. Pak Vet J. 2016;36:275-9.

18. Wen $X B$, Jiang $H T$, Zhang YL, Lang XY, Liu J, Ni HB. Rapid and sensitive diagnosis of cattle anaplasmosis by loop-mediated isothermal amplification (LAMP). Pak Vet J. 2016;36:174-8.

19. Yilmaz R, Cangul IT, Onat K, Akkoc A, Ozyigit MO, Akdesir E. Histopathological, immunohistochemical and bacteriological characterization of Mycoplasma bovis pneumonia in cattle. Pak Vet J. 2016;36:316-21.

20. Qi XY. Seroprevalence of Pseudorabies, infection in pigs in Qinghai of China. Chinese Qinghai Journal of Animal Veterinary Science. 2015;9:137-8. (in Chinese)

21. Shu XH, Yin GF, Li WG, Liu Y, Hou JF. Seroprevalence of respiratory disease, infection in pigs in some parts of Yunnan. China Animal Husbandry Veterinary. 2010;5:75-7. (in Chinese)

22. Hu D, Lv L, Zhang Z, Xiao Y, Liu S. Seroprevalence and associated risk factors of pseudorabies in Shandong province of China. J Vet Sci. 2016;17:361-8.

23. Yu X, Zhou Z, Hu D, Han T, Li X. Pathogenic pseudorabies virus, China, 2012. Emerge Infectious Disease. 2015;20:102-4.

24. Vicente J, Ruizfons F, Vidal D, Höfle U, Acevedo P, Villanúa D. Serosurvey of Aujeszky's disease virus infection in European wild boar in Spain. Vet Res. 2005;156:408-12

25. Zhang XX, Lou ZZ, Huang SY, Zhou DD, Jia WZ, Su CL, et al. Genetic characterization of Toxoplasma gondii from Qinghai vole, plateau pika and Tibetan ground-tit on the Qinghai-Tibet plateau. China Parasite Vector. 2013;6:291.

26. Zhang NZ, Zhou DH, Huang SY, Wang M, Shi XC, Ciren DB. Seroprevalence and risk factors associated with Haemophilus parasuis, infection in Tibetan pigs in Tibet. Acta Tropical. 2014;132:94-7.

27. Solymosi N, Reiczigel J, Berke O, Harnos A, Szigeti S, Fodor L, et al. Spatial risk assessment of herd sero-status of Aujeszky's disease in a county in Hungary. Prev. Vet. Med. 2004;65:9-16.

\section{Submit your next manuscript to BioMed Central and we will help you at every step:}

- We accept pre-submission inquiries

- Our selector tool helps you to find the most relevant journal

- We provide round the clock customer support

- Convenient online submission

- Thorough peer review

- Inclusion in PubMed and all major indexing services

- Maximum visibility for your research

Submit your manuscript at www biomedcentral.com/submit

) Biomed Central 